\title{
Reflexive Accounts and Accounts of Reflexivity in Qualitative Data Analysis
}

I Natasha S. Mauthner

University of Aberdeen

- Andrea Doucet

Carleton University, Canada

\begin{abstract}
While the importance of being reflexive is acknowledged within social science research, the difficulties, practicalities and methods of doing it are rarely addressed. Thus, the implications of current theoretical and philosophical discussions about reflexivity, epistemology and the construction of knowledge for empirical sociological research practice, specifically the analysis of qualitative data, remain underdeveloped. Drawing on our doctoral experiences, we reflect on the possibilities and limits of reflexivity during the interpretive stages of research. We explore how reflexivity can be operationalized and discuss reflexivity in terms of the personal, interpersonal, institutional, pragmatic, emotional, theoretical, epistemological and ontological influences on our research and data analysis processes. We argue that data analysis methods are not just neutral techniques. They reflect, and are imbued with, theoretical, epistemological and ontological assumptions - including conceptions of subjects and subjectivities, and understandings of how knowledge is constructed and produced. In suggesting how epistemological and ontological positionings can be translated into research practice, our article contributes to current debates aiming to bridge the gap between abstract epistemological discussions and the nitty-gritty of research practice.
\end{abstract}

\section{KEY WORDS}

data analysis / epistemology / methodology / methods / ontology / qualitative research / reflexivity 


\section{Introduction}

$\mathrm{n}$ an article encouraging researchers to be reflexive about how they analyse other people's accounts of their lives, it seems appropriate for us to reflect on our own account and why we are we concerned with reflexivity in qualitative data analysis. Our story begins with our doctoral research - a study of women's experiences of motherhood and postnatal depression (Mauthner, $1998,1999,2002)$ and a study of couples attempting to share childcare, housework and paid employment (Doucet, 2000, 2001). Like other students coming to qualitative research for the first time, we were overwhelmed by the amounts of data we generated. Initially, we found little guidance within our research community on how to analyse this data. The available research methods texts described what seemed to us abstract, mechanical and disembodied technical procedures we found difficult to apply to our research (Mauthner and Doucet, 1998). Further, the methods that appealed to us seemed difficult to use without the guidance of an experienced facilitator. Half way through our doctoral research, we had the opportunity of joining a small graduate research group set up by a leading visiting feminist academic whose aim was to impart a new method of data analysis she had developed collaboratively in the United States over a 20-year period. Our senior colleague proved to be a committed and enthusiastic facilitator, and we spent 17 months analysing much of our data within the context of this group. This level of input and support at the data analysis stage is rare for postgraduate students, and it sharpened our awareness of the importance of this phase of the research and of the pitfalls of glossing over the processes through which we transform individual subjective accounts into social science 'theory'.

Our interest in reflexivity generally, and as it relates to data analysis in particular, is more recent. It has developed largely in response to our increasing awareness of how limited our reflexive processes were at the time of our doctoral research, and how this was linked to our ambivalence about our role in the research, to the epistemological and other assumptions underpinning the data analysis methods we used, and to our lack of theoretical and methodological tools with which to operationalize reflexivity. As we discuss in this article, the importance of being reflexive is acknowledged within social science research and there is widespread recognition that the interpretation of data is a reflexive exercise through which meanings are made rather than found (Mauthner et al., 1998). However, reflexivity has not been translated into data analysis practice in terms of the difficulties, practicalities and methods of doing it. Instead, there is an assumption built into many data analysis methods that the researcher, the method and the data are separate entities rather than reflexively interdependent and interconnected. Most methods continue to be presented as a series of neutral, mechanical and decontextualized procedures that are applied to the data and that take place in a social vacuum. Data analysis is described as 'a range of techniques for sorting, organizing and indexing qualitative data' (Mason, 1996: 7). The 'embodied', situated and subjective researcher carrying out the analysis 
is rendered invisible as are the interpersonal, social and institutional contexts. This positivistic model of the absent or neutral researcher is reinforced by computer aided programs for qualitative data analysis as 'the use of technology confers an air of scientific objectivity onto what remains a fundamentally subjective, interpretative process' (Mauthner and Doucet, 1998: 122). In this article, we suggest that methods of data analysis are not simply neutral techniques because they carry the epistemological, ontological and theoretical assumptions of the researchers who developed them (Alvesson and Sköldberg, 2000), and they are later infused with the, sometimes different, assumptions of the researchers who use them. In arguing that data analysis methods are epistemological and ontological issues we challenge Harding's (1992) distinction between methods, methodology and epistemology (see also Edwards, 1990), as well as the division between philosophical debates about epistemology and the nature of knowledge on the one hand and more concrete discussions about research methods on the other.

Our understanding of how our data analysis processes, and projects as a whole, were influenced by such epistemological, ontological and theoretical assumptions as well as other personal, interpersonal, emotional, institutional and pragmatic influences has deepened over recent years. Time, distance and detachment from our doctoral work have allowed us to be more reflexive about our research processes. The security of a job, and a position within academia, also undoubtedly make it easier to admit and articulate the confusions and tensions we felt and how these manifested themselves in our research. Moreover, as May (1998: 159) points out, intense methodological and epistemological musing on reflexivity can run counter to the aims and time lines of the institutional organizations that fund research projects. Reflecting on our reflexive processes has therefore raised questions for us about the possibilities and limits of reflexivity. Can reflexivity be encouraged and enhanced by building it into our research methods and processes, and by creating appropriate times, spaces and contexts to be reflexive? At the same time, is there a limit to how reflexive we can be, and how far we can know and understand what shapes our research at the time of conducting it, given that these influences may only become apparent once we have left the research behind and moved on in our personal and academic lives (Doucet, 1998; Mauthner et al., 1998)? For example, our understanding of how our data analysis methods were infused with epistemological and ontological assumptions that we were not fully aware of at the time has deepened as a result of progress in our thinking about epistemology and ontology.

In this article we consider reflexivity as it relates to the analysis of qualitative data by drawing and reflecting on our respective doctoral studies. ${ }^{1} \mathrm{We}$ begin with a brief overview of the 'reflexive turn' in the social sciences, and note that reflexivity has been most widely debated in relation to theory construction and epistemology, and the data collection stages of qualitative research. We move on to consider the more limited ways in which reflexivity has been addressed within discussions of qualitative analysis of sociological data. We argue that while there is recognition that reflexivity is important in data 
analysis, in practice few researchers give reflexive accounts of data analysis or discuss how reflexivity can be operationalized. The question remains as to how researchers can incorporate their reflexive observations into the actual analysis of their data. The final section offers suggestions by discussing how we analysed our doctoral data using the voice-centred relational method of data analysis (Brown and Gilligan, 1992), a method that includes some limited tools with which to operationalize reflexivity. However, the bulk of our discussion focuses on our limited reflexive processes at the time of our research, and on the broadened understanding of reflexivity we have since developed. We draw particular attention to the ontological assumptions underpinning data analysis methods and argue that as researchers we need to be reflexive about, and articulate, the ontological nature of subjects and subjectivities we are using in our research as well as the epistemological assumptions underpinning our methods of data analysis and knowledge construction.

\section{The 'Reflexive Turn' in the Social Sciences}

The 'problem of reflexivity' and the ways in which 'our subjectivity becomes entangled in the lives of others' (Denzin, 1997: 27) are issues which have concerned sociologists (Atkinson, 1992a; Denzin, 1989, 1995; Hammersley and Atkinson, 1983; Hobbs and May, 1993; Lather, 1991) and anthropologists (Clifford and Marcus, 1986; Geertz, 1980, 1988; Marcus and Fischer, 1986; Rosaldo, 1989) for at least 30 years, and philosophers for much longer (Quine, 1969; Rorty, 1979). The 'problem' arises through the recognition that as social researchers we are integral to the social world we study and as Denzin (1994: 503 ) points out, '[r]epresentation ... is always self-presentation ... the Other's presence is directly connected to the writer's self-presence in the text'. Feminist, postmodern, post-structural, hermeneutic, interpretive and critical discourses recognize that knowledge and understanding are contextually and historically grounded, as well as linguistically constituted. Feminists have been particularly vocal on this point (Grosz, 1995; Lather, 1991; Riley, 1988) and indeed reflexivity is one of the main themes in discussions of feminist research (DeVault, 1990; Fonow and Cook, 1991; Harding, 1992; Olesen, 1994).

The 'reflexive turn' in the social sciences has contributed towards demystification and greater understanding of theoretically and empirically based knowledge construction processes. The partial, provisional and perspectival nature of knowledge claims is recognized. There is increased awareness that 'bow knowledge is acquired, organized, and interpreted is relevant to what the claims are' (Altheide and Johnson, 1994: 486). The production of theory is described as a social activity, which is culturally, socially and historically embedded, thus resulting in 'situated knowledges' (Haraway, 1988). Attention has been drawn to the linguistic and rhetorical strategies used by social scientists in reporting their research and they are urged to reflect not only on their methods of data collection and analysis, but also on their methods of writing 
and reading (Atkinson, 1992b; Clifford and Marcus, 1986; Geertz, 1973). The supposedly 'neutral' status of texts has also been questioned, as different readers interpret texts in different ways depending on their social location and perspectives (Denzin, 1994). As May (1998: 173) points out, this 'epistemology of reception' raises critical questions about 'how and under what circumstances social scientific knowledge is received, evaluated, and acted upon and under what circumstances'. The reflexive turn, and in particular postmodern and poststructuralist critiques, has thus created a sense of uncertainty and crisis as increasingly complex questions are raised concerning the status, validity, basis and authority of knowledge claims (Denzin, 1994, 1997; Geertz, 1988; Hollway, 1989; Richardson, 1997). As Denzin (1994, 1997) suggests, researchers today face a profound dual 'crisis of representation and legitimation' (see also Atkinson, 1992b; Clifford, 1986; Lather, 1991; Marcus and Fischer, 1986).

\section{Reflexivity and Research Practice}

The implications of these theoretical and philosophical discussions about reflexivity, epistemology and the construction of knowledge for empirical sociological research practice remain under-developed. ${ }^{2}$ Commentators point out that abstract, analytical and philosophical debates about the nature of knowledge and arguments about research methods are disconnected and 'moving in opposite directions' (Maynard, 1994: 22; see also Edwards, 1990). Moreover, this theoretical-empirical divide can be misleading since both theorists and empirical researchers are in the business of constructing knowledge. The differences lie more in their 'raw material' than in their knowledge-construction processes.

One area where sociological researchers have drawn links between epistemology and research practice concerns the research relationship. Indeed, reflexivity has been explored in great detail in relation to the early stages of research (for example, Hobbs and May, 1993). Feminist scholars have engaged in particularly lively debates about the extent to which similarities or differences between researcher and researched in characteristics such as gender, race, class and sexuality influence the nature and structure of research relationships (Cotterill, 1992; Edwards, 1990; Finch, 1984; Ribbens, 1989; Song and Parker, 1995). Critical reflections on the inevitability of power differentials within the various stages of research have superseded earlier emphases on reciprocity and the implicit demands on the researcher to equalize these power relations (Wolf, 1996: x).

Some, though less, attention has also been devoted to issues of power and exploitation during data analysis and interpretation (e.g. Glucksmann, 1994; Mauthner and Doucet, 1998). Scholars recognize the importance of being reflexive about how we interpret our data, our role in the analytic process, and the pre-conceived ideas and assumptions we bring to our analysis (Devine and 
Heath, 1999; Henwood and Pidgeon, 1997; Olesen et al., 1994). Researchers are encouraged to reflect on and record their interpretations, and they are reminded that the validity of their interpretations is dependent on being able to demonstrate how they were reached (Boulton and Hammersley, 1996; Mason, 1996). Strauss and Corbin (1990: 75), for example, have cautioned that 'The trouble is that researchers often fail to see much of what is there because they come to analytic sessions wearing blinders, composed of assumptions, experience, and immersion in the literature' (see also Anderson and Jack, 1991: 12).

While in principle there is recognition that reflexivity is important in data analysis, in practice, there are few examples of reflexive accounts of, or accounts of reflexivity in, qualitative data analysis. ${ }^{3}$ Instead, there is a tendency to simplify the complex processes of representing the 'voices' of respondents as though these voices speak on their own (Reinharz, 1992: 267; but see Frith and Kitzinger, 1998), rather than through the researcher who makes choices about how to interpret these voices and which transcript extracts to present as evidence.

\section{'Doing' Reflexivity in Qualitative Data Analysis: Examples from our Research}

In this section, we draw on our doctoral experiences to illustrate how using a particular data analysis method within the context of a regular research group gave us a time, a space, a context and a method for operationalizing a degree of reflexivity during the analytic stages of our research. We also draw attention to what we now regard as the limited extent of our reflexive processes and methods at the time of our research. We discuss how, with the benefit of hindsight, we have reached a greater understanding of the range of influences shaping our research, and we describe the expanded notion of reflexivity we have since developed. In particular, we suggest that reflexivity is not confined to issues of social location, theoretical perspective, emotional responses to respondents, and the need to document the research process, aspects of reflexivity which are highlighted within current literature. We demonstrate how more neglected factors such as the interpersonal and institutional contexts of research, as well as ontological and epistemological assumptions embedded within data analysis methods and how they are used, can deeply influence research processes and outcomes.

\section{Social Location and Emotional Responses to our Respondents}

Within discussions of reflexivity, attention is often drawn to the importance of recognizing the social location of the researcher as well as the ways in which our emotional responses to respondents can shape our interpretations of their accounts. However, few methods offer concrete ways of doing this. We used the 
voice-centred relational method of data analysis (Brown and Gilligan, 1992) which has these reflexive elements built in. It revolves around a set of three or more readings of the interview text. One of these readings involves a 'readerresponse' element in which the researcher reads for herself in the text. She places herself, her background, history and experiences in relation to the respondent. She reads the narrative on her own terms, listening for how she is responding emotionally and intellectually to this person (Brown, 1994: 392). In practical terms, a 'worksheet' technique is used (for this and other readings) whereby the respondent's words are laid out in one column and the researcher's reactions and interpretations are laid out in an adjacent column (Gilligan et al., 1990; Mauthner and Doucet, 1998). This allows the researcher to examine how and where some of her assumptions and views might affect her interpretation of the respondent's words, or how she later writes about the person. This reading is based on the assumption that locating ourselves socially, emotionally and intellectually allows us to retain some grasp over the blurred boundary between the respondent's narrative and our interpretation. Failure to name these emotions and responses might lead them to become expressed in other ways such as in how we write about that person. This reading is also premised on the epistemological assumption that our intellectual and emotional reactions to other people constitute sources of knowledge (see also Hammersley and Atkinson, 1983; Miles and Huberman, 1994; Mishler, 1986).

Situating ourselves socially and emotionally in relation to respondents is an important element of reflexivity. However, too much has been made of the oftrepeated references made by feminist researchers to their positioning of gender, class, ethnicity, sexuality and geographical location. As Patai (1991: 149) notes, these locations are often 'deployed as badges', which are meant to represent 'one's respects to "difference", but do not affect any aspect of the research or interpretive process. We suggest that the interplay between our multiple social locations and how these intersect with the particularities of our personal biographies needs to be considered, as far as possible, at the time of analysing data. We also recognize, however, that the benefit of hindsight can deepen this understanding of what is influencing our knowledge production and how this is occurring.

Natasha, for example, used the 'reader-response' reading of the voicecentred method to explore how the fact that she was not a mother and had not experienced postnatal depression might influence her interpretation of the women's accounts. The method helped her identify where this appeared to be limiting her understanding of aspects of their stories. However, her ability to be reflexive and articulate the nature of these limitations was enhanced by 'doing' reflexivity within the context of a research group and drawing on the insights of other researchers, particularly those who had experienced motherhood. For example, they pointed out that her interpretation of the women's accounts was premised on a negative conceptualization of motherhood and by the loss and bereavement model of motherhood informing much of the feminist literature she had been reading (see Mauthner, 2002). 


\section{Academic and Personal Biographies}

Hindsight has enabled us to understand and articulate how our doctoral research was the product of our academic and personal biographies. Natasha came to her $\mathrm{PhD}$ from a positivistic background in experimental psychology. Her disenchantment with the discipline and its positivist paradigm led her to move to a social and political sciences department in the first year of her $\mathrm{PhD}$. Despite the physical move, she still felt intellectually caught between two paradigms. While her explicit theoretical and methodological position was one in which she rejected notions of the detached, neutral, 'objective' researcher, she nevertheless felt a positivist pressure to render herself, her voice and her influence invisible in her research. This was compounded by the fact that, having not experienced motherhood herself, she viewed the women she was interviewing as 'experts' about motherhood and postnatal depression. Her tendency to privilege the women's accounts also resulted from her desire to react against the dominant research tradition in her field, in which mothers' views are devalued and disregarded (Mauthner, 1998, 2002). Here, she was influenced by feminist standpoint epistemology and the notion of 'giving voice' to marginalized groups such as women and particularly women with mental health problems. Her approach also reflected the epistemological and ontological assumptions underpinning the methodological and theoretical tradition she was using in analysing her data in which there is a tendency to romanticize women's 'voices' and 'subjectivities'.

In practical terms, these influences meant that in her attempt to prioritize the women's 'voices' she failed to acknowledge or take into account fully her subjectivity in how she analysed her data and wrote up her research. This compromised her early analysis in that, for example, she failed to go beyond the women's words to understand the psychological and cultural significance of their words - for instance, how drawing on medical explanations and discourses of their depression was important to women because it could absolve them from feelings of guilt and responsibility. Her invisibility in the research meant that although she was drawing heavily on relational theory in interpreting the women's stories, when it came to writing up her research, she implied that she had captured women's experiences and that her account of postnatal depression was a direct reflection of these experiences. She obscured the partial, perspectival and positioned nature of her account that resulted from her listening to the women's stories through a 'relational' filter - listening for a relational 'self', prioritizing her analysis on relational issues in women's accounts, and constructing a relational interpretation of postnatal depression.

Andrea came from a position of theoretical and methodological pluralism, due to her degrees in political theory, international development studies, and sociology. Her 'hybrid' position emerged gradually, beginning with her roots in marxism and socialist feminism which then combined with her later interests in the interpretivist qualitative tradition and feminist standpoint epistemology. These latter intellectual influences came out of her four years as a participatory 
research trainer in South America and her early years of feminist theoretical work for her PhD. While her socialist feminist background led her never to relinquish her belief that structures of inequality existed (i.e. a critical realist position that there was something 'out there'), she also believed that there was something 'in here' in the people she interviewed. That is, like Natasha, the enthusiasm she experienced during her first in-depth qualitative research project led her to believe that, as a 'good' researcher, she had captured the voices and at least a partial subjectivity of the people she interviewed.

With hindsight Andrea has become acutely aware of how her biography affected her choice of academic texts that guided her research, and how this combination of personal life and academic texts led her to particular ways of 'seeing' and 'hearing' during her data analysis processes. In particular, her interpretations of her interview transcripts with mothers and fathers and their stories about parenting, home life and employment, were deeply affected by the birth of her three children during the five years of her doctoral research. Recognizing the liberal feminist conception of autonomous self-sufficient individuals that underlined much of the literature on gender divisions of domestic labour, Andrea aimed to balance out this perspective through the inclusion of a relational ontology as informed by feminist work on 'care' and the 'ethic of care'. Moving towards this inclusion was very much affected by her own parenting practices and ontological connection with care and these processes, in turn, had a profound effect on her knowledge construction processes. Respondents who challenged mainstream and 'male stream' models of parenting and work were, in retrospect, accorded particular weight during data analysis processes, partly because they provided a balance to the well-established liberal and liberal feminist inspired stories on women and parenting that dominated the literature on gender and domestic labour and also because their challenges resonated with Andrea's experiences and the theoretical literature she was exploring (Doucet, 1998, 2000, 2001).

\section{Institutional and Interpersonal Contexts}

The 'choices' we make in our research with regard to ontological and epistemological positioning, methodological and theoretical perspective, and the adoption of particular research methods are bound up not only with our personal or academic biographies, nor are they motivated exclusively by intellectual concerns. The interpersonal, political and institutional contexts in which researchers are embedded also play a key role in shaping these 'decisions' (Bell and Newby, 1977; Bell and Roberts, 1984). As noted earlier, we analysed our doctoral data in the context of a research group set up by a leading visiting feminist academic who introduced us to a particular body of theoretical and methodological work. We were drawn to this work partly for intellectual reasons (Mauthner and Doucet, 1998), but also for pragmatic ones shaped by institutional constraints. Here was a well-known and highly regarded academic willing to commit substantial amounts of time to teaching us how to analyse 
qualitative data, albeit from a particular theoretical, ontological and epistemological perspective. We were not being offered this opportunity by other academic researchers at our institution where, indeed, our faculty was dominated by quantitative and positivistic approaches.

Within this context, we valued highly the support, encouragement and intellectual input offered by our senior colleague, and we were keen to sustain her interest and enthusiasm. This in part led us to draw increasingly on her work and school of thought, thus deeply shaping the methodological, theoretical, epistemological and ontological contours of our thinking and theses. In other words, the intellectual development of our research reflected the availability, support and commitment of a particular mentor, and was intimately connected to the interpersonal, political and institutional contexts of our research. As Haraway (1991: 106) points out, 'scientific stories are not innocent'; they reflect, and cannot be decontextualized from, surrounding events and institutional circumstances. Several years on, it is easier for us to understand and articulate how our research was shaped, and inevitably enabled and constrained, by our relationship with our mentor, as well as our institutional setting.

\section{Ontological and Epistemological Conceptions of Subjects and Subjectivities}

Reflexivity at the data analysis stage also means examining the ontological and epistemological assumptions built into particular methods of data analysis by those who both develop and use them. The voice-centred method we used is informed by particular ontological and epistemological assumptions. For example, it holds at its core the idea of a relational ontology in which conceptions of the separate, self-sufficient, independent, rational 'self' or 'individual' are rejected in favour of notions of 'selves-in-relation' or 'relational beings'. Human beings are viewed as interdependent rather than independent and as embedded in a complex web of intimate and larger social relations. This view is akin to sociological accounts that highlight the self in symbolic interactionist terms (see Doucet, 1998; Mauthner, 1999; Mauthner and Doucet, 1998).

At the time of our doctoral work, we were aware of and attracted to this relational world-view. The inclusion of a relational ontology provided Andrea with the basis for innovative relational thinking around domestic and community responsibilities, lives and processes (Doucet, 2000, 2001). A relational approach opened up a space for Natasha to theorize postnatal depression as a relational problem involving interpersonal and cultural 'disconnections', in contrast to existing feminist accounts that emphasized losses of identity, autonomy and independence (Mauthner, 1998, 1999, 2002). Conceiving subjects in relational terms drew our attention to aspects of our respondents' accounts that had been overlooked by previous researchers. This allowed us to make original contributions to, and further debates within, our respective research areas. 
While we both embraced relational theory, it is only in recent years that we have come to appreciate how these relational ontological and epistemological assumptions about subjects and subjectivities are implicitly embedded - but not explicitly articulated - within the voice-centred method. At the time of conducting our research, our relatively uncritical adoption of the method meant that implicitly we were aligning ourselves with the epistemological position built into the method by those who developed it. This method recognizes the importance of social context - material, ideological and discursive - as critical backdrops to research respondents' voiced experiences. It also recognizes the weighty significance of the research encounter as a site where some voices may be enhanced while others are silenced. Nevertheless, it still exhibits a leaning towards more interpretive assumptions, with hints of both phenomenological and hermeneutic approaches (Schwandt, 1998), combined with implicit feminist standpoint assumptions on the primacy of, as well as the possibility of attaining, the respondent's 'experience' or 'voice'. ${ }^{4}$ Subjects' utterances are seen as transparent passageways into their experiences and selves. Our research was implicitly informed by these epistemological concepts of subjects. As a result, despite some explicit statements we made about the importance of being reflexive, implicitly we both believed we had captured 'the' voices of our respondents, told 'their' stories and produced more accurate accounts of their lives than had previous researchers in our respective areas. In our analysis, we assumed that what a person said in an interview context gave us direct access to their subjectivity and lived experiences. We were caught in what Hollway and Jefferson (2000: 3) refer to as the 'transparent self problem' and the 'transparent account problem' (see also Frith and Kitzinger, 1998: 304-7). Our position was reinforced by the pressure we felt to be 'authoritative', to claim and defend the originality and validity of our contributions to knowledge, and by the tensions in reconciling this with postmodern and post-structuralist notions that our account is just one 'story' among an infinite number of possible stories (Denzin, 1997; Richardson, 1997; Wolf, 1992).

Only recently have we come to appreciate, and interrogate, the epistemological and ontological assumptions of subjects and subjectivities that informed both our research and the data analysis method we used. We are more cognisant of the critical importance of distinguishing between interpretive and genealogical approaches to the subject and subjectivity (Ferguson, 1991). Our current view is that subject accounts are not completely transparent but that there is nevertheless 'a relationship between people's ambiguous representations and their experiences' (Hollway and Jefferson, 2000: 3). We suggest that subjects are reflexively constituted between the researcher and the researched, and that while they are therefore always incompletely unknown, it is possible to grasp something of their articulated experience and subjectivity through a research encounter (Doucet and Mauthner, 1999).

The impacts of these critical reflections on our research have been twofold. First, we are now much more explicit about the precise ontological, epistemological and other assumptions informing our research and in particular the 
ways in which we interpret individuals' accounts of their lives. We articulate how our theories are joint constructions of knowledge produced through the interaction between respondents' accounts and how we make sense of these accounts. Second, we adopt a more critical approach towards our accounts and those of our respondents in that we pay greater attention to the conditions and constraints under which they are produced. We stress the situated, partial, developmental and modest nature of these accounts, as well as their historicity.

We would encourage researchers, both those who develop and those who use methods, to be more explicit about the particular epistemological and ontological concepts of subjects that are informing their research practices, their analysis and ultimately their research accounts. Critical issues to be recognized include whether we are talking about an individuated or a relational subject (Benhabib, 1992; Gilligan, 1988; Tronto, 1993). Is the subject's voice one that can be rendered transparent or is it viewed as an interactive resource between different research subjects (Frith and Kitzinger, 1998)? Is the subject's account regarded as meaningful only in the particular research context in which it was produced? Are subjects discursively constituted (Butler, 1995) or discursively and materially located (Benhabib, 1995)? Is the subject viewed as data to be discovered or, alternatively, constructed (Ferguson, 1991)? In a similar vein, are subjects sources of self-reflective accounts or rather 'data to be accounted for' (Ferguson, 1991; Weedon, 1987)?

We suggest that the particular conceptions employed are less important than the epistemological accountability involved in making these conceptions as transparent as possible for the readers of our research accounts (Doucet and Mauthner, 2002). Just as Guba and Lincoln have argued that 'facts are only facts within some theoretical framework' (1998: 199), we argue that research which relies on the interpretation of subject accounts can only make sense with a high degree of reflexivity and awareness about the epistemological, theoretical and ontological conceptions of subjects and subjectivities that bear on our research practices and analytic processes (Frith and Kitzinger, 1998; Hollway and Jefferson, 2000). More generally, then, we are encouraging greater reflection and accountability on the part of researchers rather than a 'literal' accounting of the multiple filters and forces on our research. We suggest that the more researchers can be self-conscious about, and articulate, their role in research processes and products, the more readers can engage in symbolic dialogues with the author(s) and the more their confidence in the work will increase.

\section{Conclusions}

Our aim in writing this article has been to draw particular attention to reflexivity at the data analysis and interpretation stages of research, and in doing so to illustrate the inseparability of epistemology, ontology and research practice. We suggest that despite the 'reflexive turn' within the social sciences, and the call on researchers to be reflexive about their research practices, researchers are 
still offered little guidance on how to identify, articulate and take account of the range of influences shaping their research at the data analysis stage. By drawing on our doctoral experiences, we have given an example of one particular data analysis method that offers researchers a concrete way of tracing some of these influences during the interpretive process. Our experiences point to the importance not only of building reflexivity into methods of data analysis, but also of creating dedicated times, spaces and contexts within which to be reflexive (see also Siltanen, 2001). In our case, regular meetings with our research group significantly enhanced our ability to be reflexive about what we were doing when we were in the thick of our research. At the same time, we need to recognize that a profound level of self-awareness and self-consciousness is required to begin to capture the perspectives through which we view the world, and that it may be impossible to grasp the unconscious filters through which we experience events. No matter how aware and reflexive we try to be, as Grosz (1995: 13) points out, 'the author's intentions, emotions, psyche, and interiority are not only inaccessible to readers, they are likely to be inaccessible to the author herself'. There may be limits to reflexivity, and to the extent to which we can be aware of the influences on our research both at the time of conducting it and in the years that follow. It may be more useful to think in terms of 'degrees of reflexivity', with some influences being easier to identify and articulate at the time of our work while others may take time, distance and detachment from the research. As we have discussed, our deepening understanding of reflexivity - and the range of personal, interpersonal, institutional, pragmatic, emotional, theoretical, epistemological and ontological influences on our research - has only come through emotional and intellectual distance from our projects.

\section{Acknowledgements}

We are indebted to the mothers and fathers who agreed to take part in our respective research studies. We thank Carol Gilligan, Martin Richards and Robert Blackburn for the support, encouragement and insights they continue to give us in our work. Financial support for our research was provided by the Medical Research Council of the United Kingdom, and the Commonwealth Association and the Social Sciences and Humanities Research Council of Canada, respectively. Our article has benefited from valuable discussions with Keith Hart, and from three anonymous referees' comments.

\section{Notes}

1 Data analysis is not a discrete and separate stage of the research process but rather ongoing throughout and beyond the life time of a project. For the purposes of this article, however, we concentrate specifically on reflexive processes during the data analysis rather than data collection stages of qualitative 
research, as the former have received considerably less attention than the latter. We also focus on qualitative research, but acknowledge that the issue of reflexivity is equally central to quantitative research and note that there is a move within sociology to interpret quantitative data in the context of who did the collection and for what purposes (Cicourel, 1976; Hammersley and Atkinson, 1983).

2 Debates within anthropology, however, have been more prolific and have explored the politics and poetics of ethnography, and literary and theoretical reflexivity in ethnographic practice, reading and writing (Clifford, 1988; Clifford and Marcus, 1986; Geertz, 1988; Marcus and Fischer, 1986; Rosaldo, 1989; Tyler, 1985; Wolf, 1992). These debates have been particularly central to feminist methodological discussions within anthropology (and cognate disciplines) since the 1960s (e.g. Strathern, 1972). Indeed, some have argued that for the past two or three decades, innovation in anthropology has been synonymous with feminist work (Grimshaw and Hart, 1995; see Moore, 1988; Strathern, 1988).

3 Exceptions include Strauss and Corbin (1990) who discuss a range of techniques researchers can use in data analysis to make use of the sensitizing nature of their previous education and practice. Miles and Huberman (1984) provide a detailed 'documentation form' which can be used to track and record data reduction processes, data display and conclusion-drawing operations, although interestingly they later note that they are not aware of instances where this form has been used by other researchers (Miles and Huberman, 1994). Another area where reflexivity is integral to data analysis is discourse analysis (Frith and Kitzinger, 1998). Through an analysis and critique of the work of other scholars, Devine and Heath (1999) illustrate how personal biography and politics, values and beliefs can influence research processes and products, including selective use of data and prioritization of certain accounts over others during the data analysis stage.

4 More specifically, the method has its roots in clinical and literary approaches, interpretative and hermeneutic traditions, and relational theory (see Mauthner and Doucet, 1998: 125).

\section{References}

Alvesson, M. and K. Sköldberg (2000) Reflexive Methodology: New Vistas for Qualitative Research. London: Sage.

Altheide, D.L. and J.M. Johnson (1994) 'Criteria for Assessing Interpretive Validity in Qualitative Research', in N.K. Denzin and Y.S. Lincoln (eds) Handbook of Qualitative Research. London: Sage.

Anderson, K. and D. Jack (1991) 'Learning to Listen: Interview Techniques and Analysis', in S. Gluck and D. Patai (eds) Women's Words: The Feminist Practice of Oral History. London: Routledge and Kegan Paul.

Atkinson, P. (1992a) 'The Ethnography of a Medical Setting: Reading, Writing and Rhetoric', Qualitative Health Research 2: 451-74.

Atkinson, P. (1992b) Understanding Ethnographic Texts. London: Sage.

Bell, C. and H. Newby (eds) (1977) Doing Sociological Research. London: Allen \& Unwin. 
Bell, C. and H. Roberts (eds) (1984) Social Researching: Politics, Problems, Practice. London: Routledge and Kegan Paul.

Benhabib, S. (1992) Situating the Self. Cambridge: Polity Press.

Benhabib, S. (1995) 'Feminism and Postmodernism', in S. Benhabib, J. Butler, D. Cornell and N. Fraser Feminist Contentions: A Philosophical Exchange. London: Routledge and Kegan Paul.

Boulton, D. and M. Hammersley (1996) 'Analysis of Unstructured Data', in R. Sapford and V. Judd (eds) Data Collection and Analysis. London: Sage.

Brown, L.M. (1994) 'Standing in the Crossfire: A Response to Tavris, Gremmen, Lykes, Davis and Contratto', Feminism and Psychology 4: 382-98.

Brown, L.M. and C. Gilligan (1992) Meeting at the Crossroads: Women's Psychology and Girls' Development. Cambridge, MA: Harvard University Press.

Butler, J. (1995) 'Contingent Foundations', in S. Benhabib, J. Butler, D. Cornell and N. Fraser (eds) Feminist Contentions: A Philosophical Exchange. London: Routledge and Kegan Paul.

Cicourel, A. (1976) The Social Organization of Juvenile Justice. London: Heinemann.

Clifford, J. (1986) 'Introduction: Partial Truths', in J. Clifford and G.E. Marcus (eds) Writing Culture: The Poetics and Politics of Ethnography. Berkeley and Los Angeles: University of California Press.

Clifford, J. (1988) The Predicament of Culture: Twentieth-century Ethnography, Literature, and Art. Cambridge, MA: Harvard University Press.

Clifford, J. and G. Marcus (eds) (1986) Writing Culture: The Poetics and Politics of Ethnography. Berkeley: University of California Press.

Cotterill, P. (1992) 'Interviewing Women: Issues of Friendship, Vulnerability, and Power', Women's Studies International Forum 15: 593-606.

Denzin N.K. (1989) Interpretive Biography. Thousand Oaks, CA: Sage.

Denzin, N.K. (1994) 'The Art and Politics of Interpretation', in N.K. Denzin and Y.S. Lincoln (eds) Handbook of Qualitative Research. London: Sage.

Denzin, N.K. (1995) 'The Poststructuralist Crisis in the Social Sciences', in R.H. Brown (ed.) Writing Postmodernism. Urbana: University of Illinois Press.

Denzin, N.K. (1997) Interpretive Ethnography: Ethnographic Practices for the 21st Century. London: Sage.

DeVault, M.L. (1990) 'Talking and Listening From Women's Standpoint: Feminist Strategies for Interviewing and Analysis', Social Problems 37(1): 96-116.

Devine, F. and S. Heath (1999) Sociological Research Methods in Context. Basingstoke: Macmillan.

Doucet, A. (1998) 'Interpreting Mother-work: Linking Methodology, Ontology, Theory and Personal Biography', Canadian Woman Studies 18: 52-8.

Doucet, A. (2000) “"There's a Huge Gulf Between me as a Male Carer and Women”: Gender, Domestic Responsibility, and the Community as an Institutional Arena', Community, Work and Family 3: 163-84.

Doucet, A. (2001) "“You see the Need Perhaps More Clearly than I have:" Exploring Gendered Processes of Domestic Responsibility', Journal of Family Issues 22: 328-57.

Doucet, A. and N. Mauthner (1999) 'Subjects and Subjectivities in Feminist Theory and Research', Paper to the BSA Annual Conference, Glasgow. 
Doucet, A. and N.S. Mauthner (2002) 'Knowing Responsibly: Linking Ethics, Research Practice and Epistemology', in M. Mauthner, M. Birch, J. Jessop and T. Miller (eds) Ethics in Qualitative Research. London: Sage.

Edwards, R. (1990) 'Connecting Method and Epistemology: A White Woman Interviewing Black Women', Women's Studies International Forum 13: 477-90.

Ferguson, K.E. (1991) 'Interpretation and Genealogy in Feminism', Signs: Journal of Women in Culture and Society 16: 322-39.

Finch, J. (1984) "'It's Great to Have Someone to Talk to": The Ethics and Politics of Interviewing Women', in C. Bell and H. Roberts (eds) Social Researching: Politics, Problems, Practice. London: Routledge and Kegan Paul.

Fonow, M.M. and J.A. Cook (eds) (1991) Beyond Methodology: Feminist Scholarship as Lived Research. Bloomington: Indiana University Press.

Frith, H. and H. Kitzinger (1998) " "Emotion Work" as a Participant Resource: A Feminist Analysis of Young Women's Talk-in-interaction', Sociology 32: 299-320.

Geertz C. (1973) The Interpretation of Culture. New York: Basic Books.

Geertz C. (1980) 'Blurred Genres', American Scholar 49: 165-79.

Geertz, C. (1988) Works and Lives: The Anthropologist as Author. Stanford, CA: Stanford University Press.

Gilligan, C. (1988) 'Remapping the Moral Domain: New Images of the Self in Relationship', in C. Gilligan, J.V. Ward, J.M. Taylor (with Betty Bardige) (eds) Mapping the Moral Domain: A Contribution of Women's Thinking to Psychological Theory and Education. Cambridge, MA: Harvard University Press.

Gilligan, C., L.M. Brown and A. Rogers (1990) 'Psyche Embedded: A Place for Body, Relationships and Culture in Personality Theory', in A.I. Rabin, R. Zucker, R. Emmons and S. Frank (eds) Studying Persons and Lives. New York: Springer.

Glucksmann, M. (1994) 'The Work of Knowledge and the Knowledge of Women's Work', in M. Maynard and J. Purvis (eds) Researching Women's Lives from a Feminist Perspective. London: Taylor and Francis.

Grimshaw, A. and K. Hart (1995) 'The Rise and Fall of Scientific Ethnography', in A. Ahmed and C. Shore (eds) The Future of Anthropology: Its Relevance to the Contemporary World. London: Athlone.

Grosz, E. (1995) Space, Time and Perversion. London: Routledge and Kegan Paul.

Guba, E. and Y.S. Lincoln (1998) 'Competing Paradigms in Qualitative Research', in N.K. Denzin and Y.S. Lincoln (eds) The Landscape of Qualitative Research: Theories and Issues. London: Sage.

Hammersley, M. and P. Atkinson (1983) Ethnography: Principles in Practice. London: Tavistock.

Haraway, D. (1988) 'Situated Knowledges: The Science Question in Feminism and the Privilege of Partial Perspective', Feminist Studies 14: 575-99.

Haraway, D. (1991) Simians, Cyborgs and Women. New York: Routledge and Kegan Paul.

Harding, S. (1992) Whose Science? Whose Knowledge? Milton Keynes: Open University Press.

Henwood, K. and N. Pidgeon (1997) 'Using Grounded Theory in Psychological Research', in N. Hayes (ed.) Doing Qualitative Analysis in Psychology. Hove: Psychology Press. 
Hobbs, D. and T. May (eds) (1993) Interpreting the Field: Accounts of Ethnography. Oxford: Clarendon Press.

Hollway, W. (1989) Subjectivity and Method in Psychology: Gender, Meaning and Science. London: Sage.

Hollway, W. and T. Jefferson (2000) Doing Qualitative Research Differently: Free Association, Narrative and the Interview Method. London: Sage.

Lather P. (1991) Getting Smart. New York: Routledge.

Marcus, G. and M. Fischer (1986) Anthropology as Cultural Critique: An Experimental Moment in the Human Sciences. Chicago: University of Chicago Press.

Mason, J. (1996) Qualitative Researching. London: Sage.

Mauthner, N.S. (1998) “"It's a Woman's Cry for Help”: A Relational Perspective on Postnatal Depression', Feminism \& Psychology 8: 325-55.

Mauthner, N.S. (1999) “ "Feeling Low and Feeling Really Bad about Feeling Low”: Women's Experiences of Motherhood and Postpartum Depression', Canadian Psychology 40: 143-61.

Mauthner, N.S. (2002) The Darkest Days of My Life: Stories of Postpartum Depression. Cambridge, MA: Harvard University Press.

Mauthner, N.S. and A. Doucet (1998) 'Reflections on a Voice-centred Relational Method: Analysing Maternal and Domestic Voices', in J. Ribbens and R. Edwards (eds) Feminist Dilemmas in Qualitative Research: Public Knowledge and Private Lives. London: Sage.

Mauthner, N.S., O. Parry and K. Backett-Milburn (1998) “ "The Data are out There, or are They?" Implications for Archiving and Revisiting Qualitative Data', Sociology 32: 733-45.

May, T. (1998) 'Reflections and Reflexivity', in T. May and M. Williams (eds) Knowing the Social World. Buckingham: Open University Press.

Maynard, M. (1994) 'Methods, Practice and Epistemology', in M. Maynard and J. Purvis (eds) Researching Women's Lives from a Feminist Perspective. London: Taylor and Francis.

Miles, M. and M. Huberman (1984) Qualitative Data Analysis: A Sourcebook of New Methods. London: Sage.

Miles, M. and M. Huberman (1994) 'Data Management and Analysis Methods', in N.K. Denzin and Y.S. Lincoln (eds) Handbook of Qualitative Research. London: Sage.

Mishler, E.G. (1986) Research Interviewing: Context and Narrative. Cambridge, MA: Harvard University Press.

Moore, H. (1988) Feminism and Anthropology. Cambridge: Polity.

Olesen, V. 1994) 'Feminisms and Models of Qualitative Research', in N.K. Denzin and Y.S. Lincoln (eds) Handbook of Qualitative Research. London: Sage.

Olesen, V., N. Droes, D. Hatton, N. Chico and L. Schatzman (1994) 'Analyzing Together: Recollections of a Team Approach', in A. Bryman and R. Burgess (eds) Analysing Qualitative Data. London: Routledge and Kegan Paul.

Patai, D. (1991) 'U.S. Academics and Third World Women: Is Ethical Research Possible?', in S.B. Gluck and D. Patai (eds) Women's Words: The Feminist Practice of Oral History. New York: Routledge and Kegan Paul.

Quine W.V. (1969) Ontological Relativity and Other Essays. New York: Colombia University Press. 
Reinharz, S. (1992) Feminist Methods in Social Research. Oxford: Oxford University Press.

Ribbens, J. (1989) 'Interviewing - An Unnatural Situation?', Women's Studies International Forum 12(6): 579-92.

Richardson, L. (1997) Fields of Play: Constructing an Academic Life. New Brunswick, NJ: Rutgers University Press.

Riley, D. (1988) 'Am I That Name': Feminism and the Category of 'Women' in History. Minneapolis: University of Minnesota Press.

Rorty R. (1979) Philosophy and the Mirror of Nature. Princeton: Princeton University Press.

Rosaldo, R. (1989) Culture and Truth: The Remaking of Social Analysis. Boston, MA: Beacon.

Schwandt, T.A. (1998) 'Constructivist, Interpretivist Approaches to Human Inquiry', in N.K. Denzin and Y.S. Lincoln (eds) The Landscape of Qualitative Research: Theories and Issues. London: Sage.

Siltanen, J. (2001) 'Accountability in Qualitative Research: Working Reflexively as a Team', Paper presented to the Cambridge Stratification Seminar, Fitzwilliam College, Cambridge.

Song, M. and I. Parker (1995) 'Commonality, Difference, and the Dynamics of Disclosure in In-depth Interviewing', Sociology 29: 241-56.

Strathern, M. (1972) Women in Between: Female Roles in a Male World: Mount Hagen, New Guinea. London: Seminar Press.

Strathern, M. (1988) The Gender of the Gift: Problems with Women and Problems with Society in Melanesia. Berkeley: University of California Press.

Strauss, A.L. and J. Corbin (1990) Basics of Qualitative Research: Grounded Theory Procedures and Techniques. London: Sage.

Tronto, J. (1993) Moral Boundaries: A Political Argument for an Ethic of Care. New York and London: Routledge and Kegan Paul.

Tyler, S.A. (1985) The Unspeakable: Discourse, Dialogue, and Rhetoric in the Postmodern World. Madison: University of Wisconsin Press.

Weedon, C. (1987) Feminist Practice and Poststructuralist Theory. Oxford: Blackwell Publishers.

Wolf, D. (1996) 'Situating Feminist Dilemmas in Fieldwork', in D. Wolf (ed.) Feminist Dilemmas in Fieldwork. Boulder, CO: Westview Press.

Wolf, M. (1992) A Thrice-Told tale: Feminism, Postmodernism and Ethnographic Responsibility. Stanford, CA: Stanford University Press.

\section{Natasha S. Mauthner}

Is Deputy Director of the Arkleton Centre for Rural Development Research at the University of Aberdeen. Her areas of research interest include work and family life, health and mental health issues, and qualitative research theory and practice. Her current research focuses on work-family configurations in rural areas, and the impact of economic restructuring within the oil and gas industry on workers, families and children. Address: Deputy Director, Arkleton Centre for Rural Development Research, University of Aberdeen, St Mary's, King's College, Old Aberdeen AB24 3UF. E-mail:n.mauthner@abdn.ac.uk 


\section{Andrea Doucet}

Is Associate Professor in the Department of Sociology and Anthropology at Carleton University in Ottawa, Canada, where she teaches and publishes on gender, domestic life and qualitative methodologies. Her current research is on economic restructuring, fatherhood and masculinities.

Address: Associate Professor, Department of Sociology and Anthropology, Carleton University, Ottawa, Ontario, Canada KIS 5B6.

E-mail: adoucet@ccs.carleton.ca 